\title{
Measurement of lightning-induced currents in an experimental coaxial buried cable
}

\author{
E. Petrache ${ }^{1}$, M. Paolone ${ }^{2}$, F. Rachidi ${ }^{1}$, C.A. Nucci ${ }^{2}$, V. Rakov ${ }^{3}$, M. Uman ${ }^{3}$, \\ D. Jordan ${ }^{3}$, K. Rambo ${ }^{3}$, J. Schoene ${ }^{3}$, A. Cordier ${ }^{4}$, T. Verhaege ${ }^{4}$ \\ 1 Swiss Federal Institute of Technology, EMC Group, Lausanne, Switzerland \\ 2 University of Bologna, Dept. of Electrical Engineering, Bologna, Italy \\ 3 University of Florida, Dept. of Electrical and Computer Engineering, Gainesville, FL, USA \\ 4 Alcatel Submarine Networks Division, Villarceaux, France
}

\begin{abstract}
We present in this paper experimental results obtained at the International Center for Lightning Research \& Testing (ICLRT), Camp Blanding, Florida, where currents induced by triggered and natural lightning events were measured at one end of a shielded buried cable, both in the cable shield and in the inner conductor. The horizontal magnetic field was also measured. For the natural lightning events, the recorded waveforms are correlated with the data obtained by the U.S. National Lightning Detection Network (NLDN).

The paper provides also a discussion of the correlation between the horizontal magnetic field and the induced current, as well as of the effect of lightning stroke position and distance from the buried cable on the induced disturbances.
\end{abstract}

Index Terms-Lightning, induced currents, buried cables, coaxial cables.

\section{INTRODUCTION}

THE problem of lightning-induced disturbances on buried cables has recently received considerable attention (e.g. [1,2]). Even though extensive experimental investigations have been performed on the effect of indirect lightning on overhead lines (e.g. $[3,4]$ ), to the best of our knowledge, for buried cables such an experimental characterization is not available in the scientific literature. The paper presents experimental results obtained at the International Center for Lightning Research \& Testing (ICLRT), Camp Blanding, Florida. During Summer 2002, current induced by triggered and natural lightning was measured at one end of a distribution network coaxial buried cable, both in the cable shield and in the inner conductor. Simultaneously, the horizontal magnetic field and the lightning return stroke current (for triggered events) were also measured. For the natural events, the recorded induced current waveforms are correlated with the data obtained by the U.S. National Lightning Detection Network (NLDN).

The paper is aimed at providing a data set of simultaneous measurements of triggered/natural lightning events and the relevant induced currents in a buried coaxial cable, which can be of particular importance for model validation. Finally, the obtained data provide some indication of the adequacy of some typically accepted assumptions. The paper also provides a discussion of the correlation between the horizontal magnetic field and the induced current, as well as of the effect of lightning stroke position and distance from the buried cable on the induced disturbances.

\section{Cable Characteristics}

The underground cable is a $15-\mathrm{kV}$ XLPE coaxial power cable, approximately $140-\mathrm{m}$ long, covered with an insulating jacket (see Fig. 1).

The geometrical characteristics of the cable are given in Fig. 2. The cable is contained within a PVC pipe of $11 \mathrm{~cm}$ diameter and $0.7 \mathrm{~cm}$ thickness and buried at a depth of $0.9 \mathrm{~m}$.

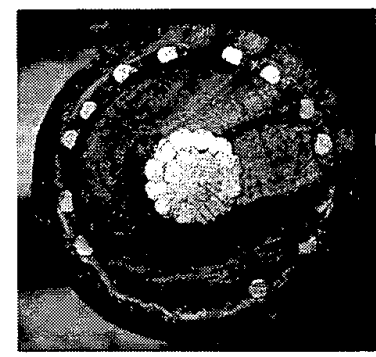

Fig. 1. Cable cross-section.

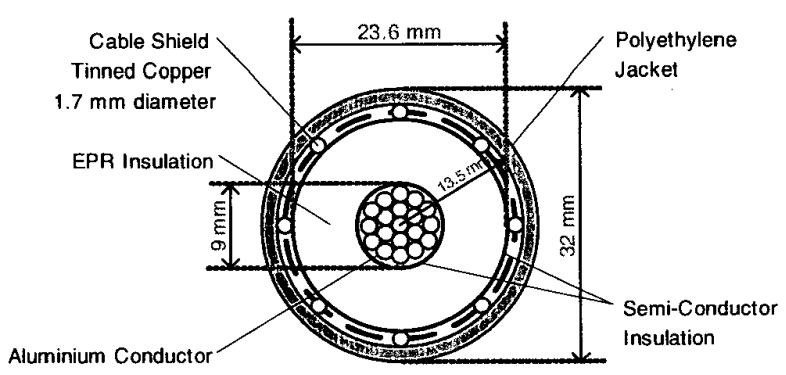

Fig. 2. Geometrical parameters of the cable.

The transfer impedance of the cable has been measured at the EMC laboratory of the Swiss Federal Institute of Technology in Lausanne using a triaxial-adapted measurement set up [5]. The results are presented in Fig. 3. 


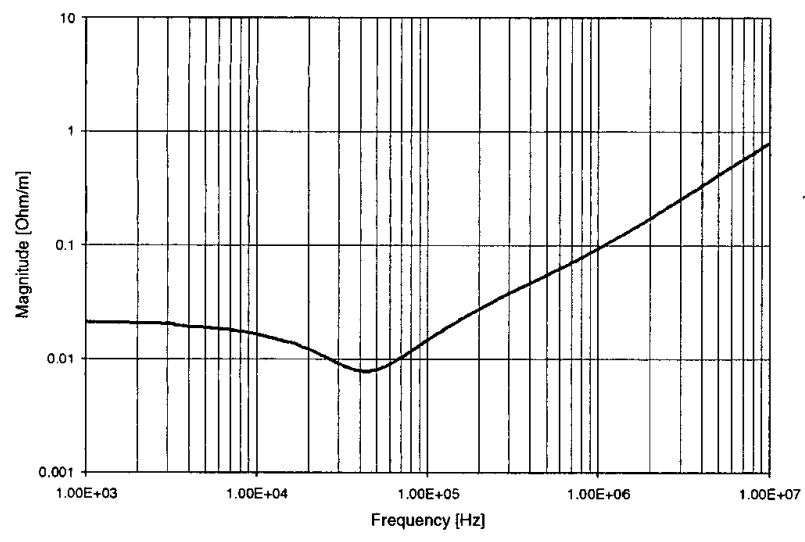

(a)

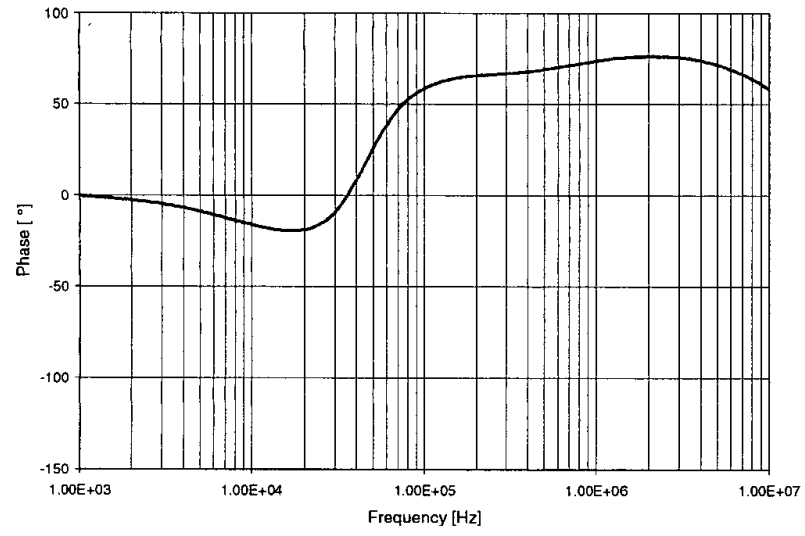

(b)

Fig. 3. Transfer impedance of the shielded cable. (a) magnitude; (b) phase.
The magnitude of the transfer impedance as a function of frequency exhibits a typical behavior, namely a decrease as the frequency increases from about 3 to $30 \mathrm{kHz}$ due to the skin effect, and an increase in the higher frequency range due to the field penetration into the cable shield. It can be seen that the magnitude of the transfer impedance reaches a value of about $1 \Omega / \mathrm{m}$ at $10 \mathrm{MHz}$.

\section{EXPERIMENTAL SET-UP}

As mentioned in the Introduction, this paper concerns the current measurements on a buried cable induced by (i) triggered and (ii) natural lightnings. The topology of the experimental set-up is shown in Fig. 4. Concerning the triggered lightning events, the rockets were launched from two different launchers: (1) a 20-m high tower launcher located $60 \mathrm{~m}$ away in the prolongation from the line left-end, and (2) a ground launcher located on the side of the line, as indicated in Fig. 4.

The terminations of the cable are placed inside metallic boxes located in Instrument Stations (IS) 1 and 2 (see Figs. 4,5 ). The inner conductor was terminated with $50 \Omega$ resistors or was short-circuited to the shield. The shield of the cable was connected directly to a vertical ground electrode at each of its extremities. The ground electrodes were cylindrical vertical rods of $12 \mathrm{~m}$ (IS1) and $24 \mathrm{~m}$ (IS2) length, respectively. The measured value of the DC grounding resistance was $60 \Omega$ for the ground electrode of IS1 and $37 \Omega$ for the ground electrode of IS2. The conductivity of the soil was experimentally determined to be in the range $1.6 \cdot 10^{-3} \mathrm{~S} / \mathrm{m}$ to $1.8 \cdot 10^{-3} \mathrm{~S} / \mathrm{m}$.

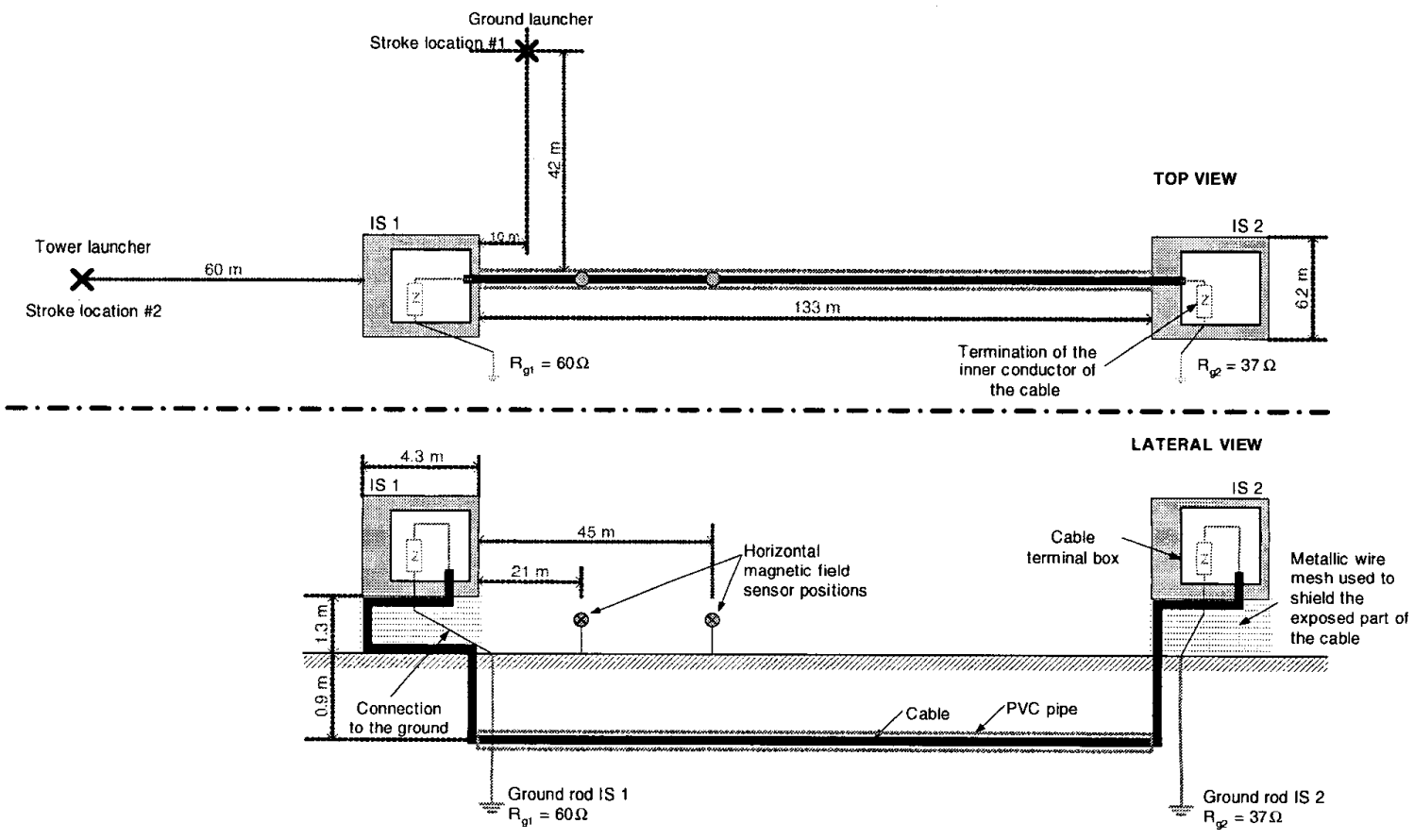

Fig. 4. Buried cable experimental set-up and positions of the triggered lightning strokes. 
During summer 2002, different events related to both triggered and natural lightning were recorded. Simultaneous measurements of lightning return stroke current (in the case of triggered lightning), horizontal magnetic field (perpendiculars to the line), and currents induced in the shield and in the inner conductor of the cable at the IS2 termination were obtained.

The lightning stroke current was measured by means of two T\&M Research Products Inc. current shunts (R-5600-8) located at the rocket launcher. The magnetic field was measured using a loop antenna sensor (TSN 245-H32, Thomson CSF) located at different positions shown in Fig. 4 and having a bandwidth of $1 \mathrm{kHz}$ to $130 \mathrm{MHz}$. The induced currents were measured using the following sensors: for the inner conductor an Eaton 112 current transformer with a bandwidth of $10 \mathrm{kHz}$ to $200 \mathrm{MHz}$, for the shield conductor, a Pearson 110 current transformer with a bandwidth of $1 \mathrm{~Hz}$ to $20 \mathrm{MHz}$. The measured signals from all the sensors were relayed via optical fiber cables to a receiver and an 8-bit digitizing oscilloscope operating at $100 \mathrm{Msamples} / \mathrm{sec}$. The digitizer features a segmented memory (1 Mbyte per 4 channels), which is used to record waveshapes for up to 10 strokes per lightning flash with a time window of $100 \mu$ s per flash.

Pictures presented in Fig. 5 show the instruments stations IS1 and IS2, the two launchers, and their relative positions.

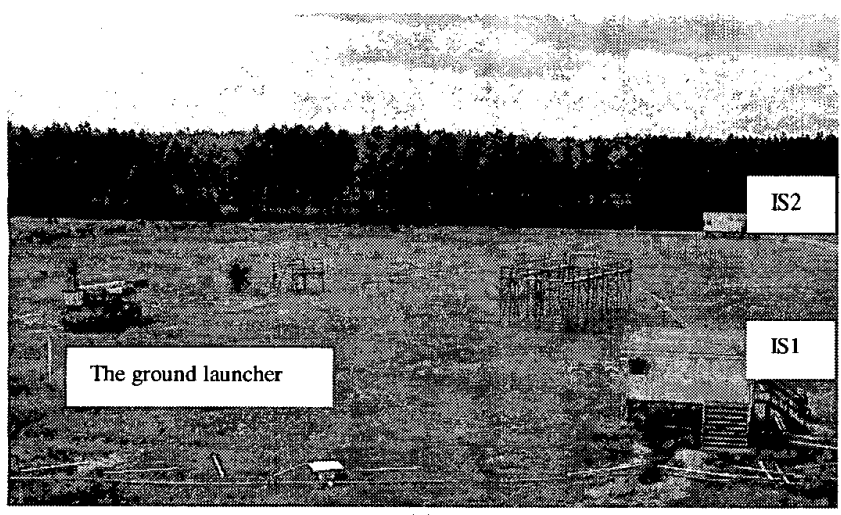

(a)

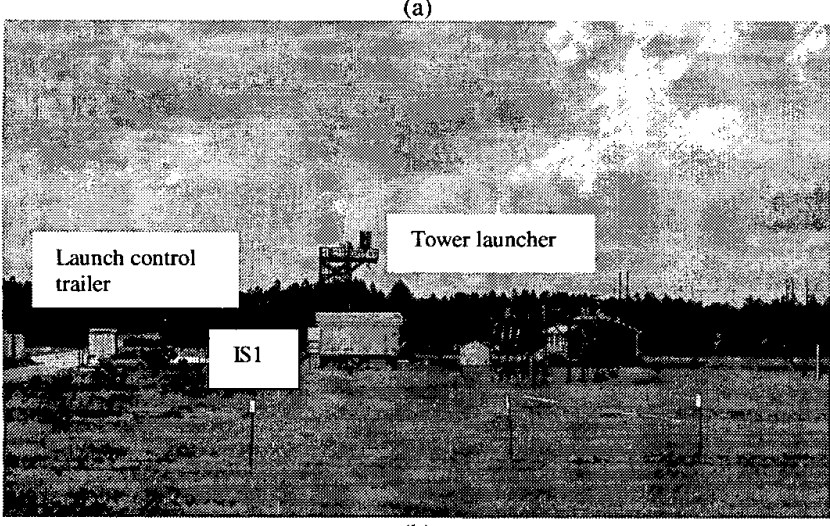

(b)

Fig. 5. Instrument Stations 1 and 2 and their position with respect to the launchers. (a) view from the tower launcher; (b) view from IS2.

\section{Measurement Results}

\section{A. Induced currents from lightning strokes at close range (triggered lightning)}

We present in this section two sets of experimental data obtained for stroke locations 1 and 2, as shown in Fig. 4.

\section{Stroke location 1 (recorded on August $18^{\text {th }}, 2002$ )}

For this event, the inner conductor was terminated at each ends with a $50 \Omega$ resistor located in the metallic boxes shown in Fig. 4, a value close to that of the surge impedance of the cable (about $58 \Omega$ ). The magnetic field sensor was placed 45 meters from IS1 along the path of the buried cable (See Fig. 4).

Fig. 6 presents simultaneous measurements of the lightning return stroke current, magnetic field, induced current in the cable shield at IS2, and induced current in the inner conductor at IS2.

\section{Stroke location 2 (recorded on July $25^{\text {th }}, 2002$ )}

Fig. 7 presents the waveforms corresponding to the second return stroke of a four-stroke flash recorded on July $25^{\text {th }}$, 2002. For this case, the lightning current was not measured directly. However, from the magnetic field measurement, its peak value can be estimated to be about $11 \mathrm{kA}$. During this event, the inner conductor of the buried cable was terminated on a $50 \Omega$ resistor in IS1, and was short circuited in IS2. The magnetic field sensor was located at about $21 \mathrm{~m}$ from IS1 along the path of the cable (see Fig. 4).

We can see from Figs. 6 and 7 that the induced current in the shield of the cable can reach large values about $100 \mathrm{~A}$. In both cases, the shield current has a unipolar waveshape with a HPW (half-peak width) duration of about $5 \mu \mathrm{s}$, shorter than the FWHM of the return stroke current (about $30 \mu \mathrm{s}$ ), as well as that of the magnetic field (about $10 \mu \mathrm{s}$ ).

Note additionally that, for similar lightning current peak and waveshape, the induced current peak on the cable shield for stroke location 1 ('side stroke') is twice as large as the one for stroke location 2.

It can also be seen that, similar to the case of overhead lines [7], the induced current for stroke location 1 is higher than that corresponding to stroke location 2.

Finally, it is important to note that, due to the high value of the cable transfer impedance, the current in the inner conductor is a non-negligible fraction of the shield current. As a consequence, the common weak coupling assumption when calculating the response of such a cable might not be adequate.

\section{B. Induced currents from lightning strokes at distant ranges (natural lightning)}

During Summer 2002, in addition to the triggered lightning events, we recorded simultaneous waveforms of magnetic field and induced currents in the buried cable due to natural lightning events. 


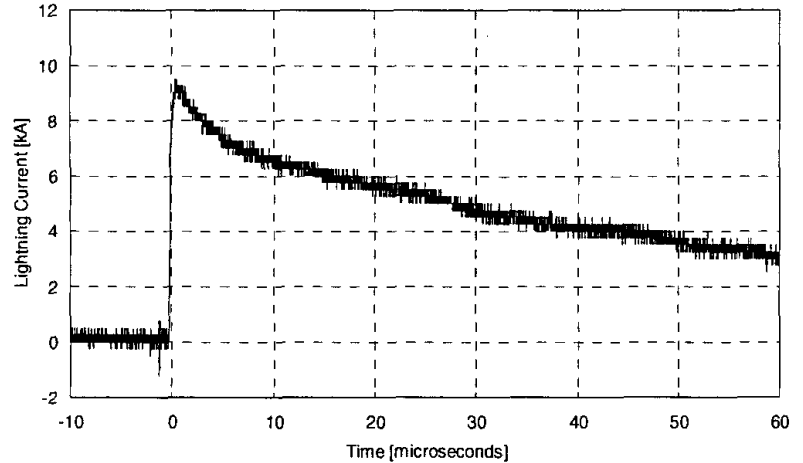

(a)

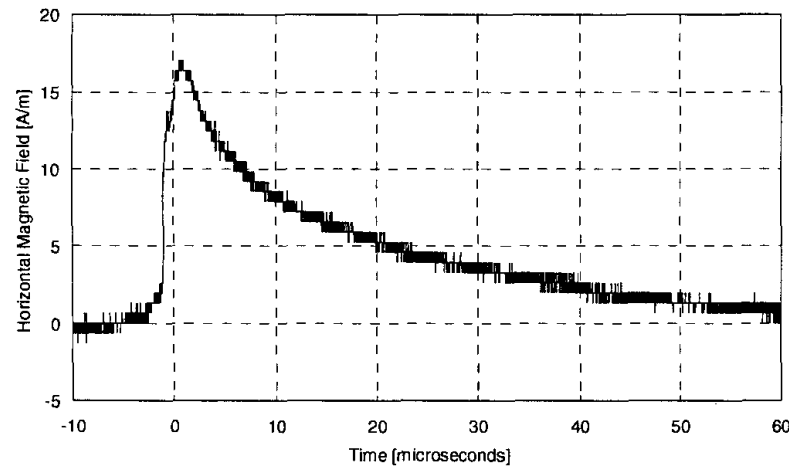

(b)

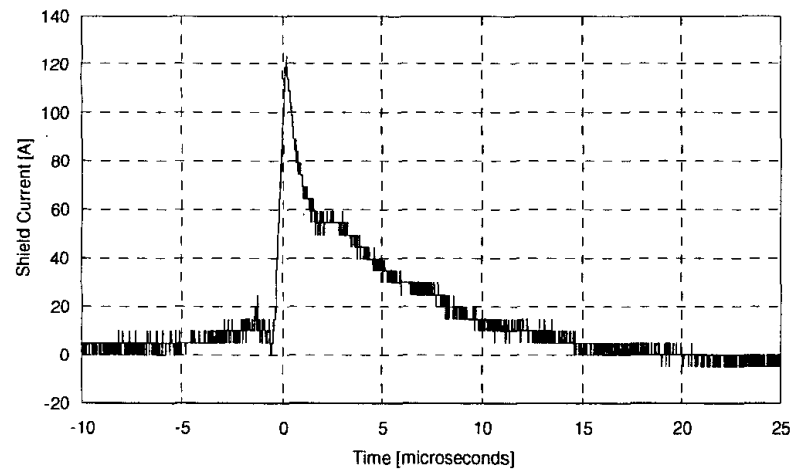

(c)

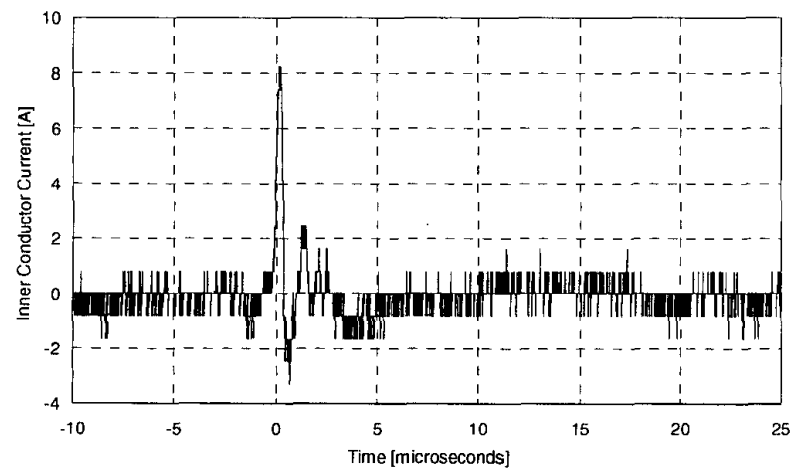

(d)

Fig. 6. Event recorded on August $18^{\text {th }}, 2002$. Stroke location 1.

(a) Return stroke current. (b) Horizontal magnetic field. (c) Induced current in the cable shield at IS2. (d) Induced current in the inner conductor at IS2.

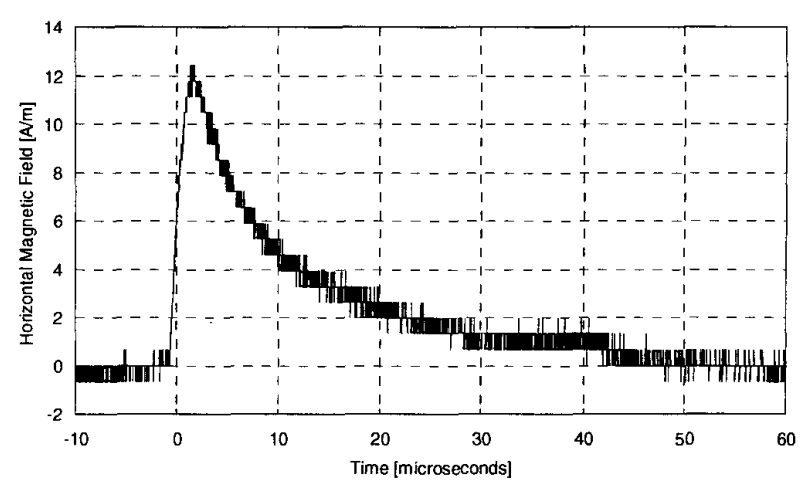

(a)

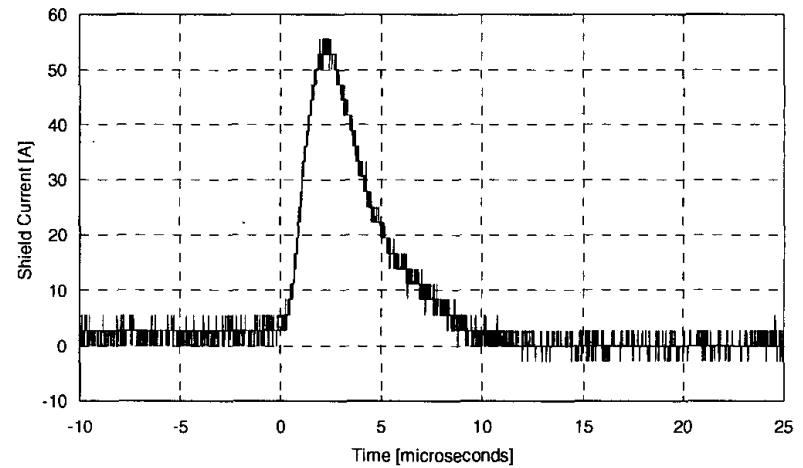

(b)

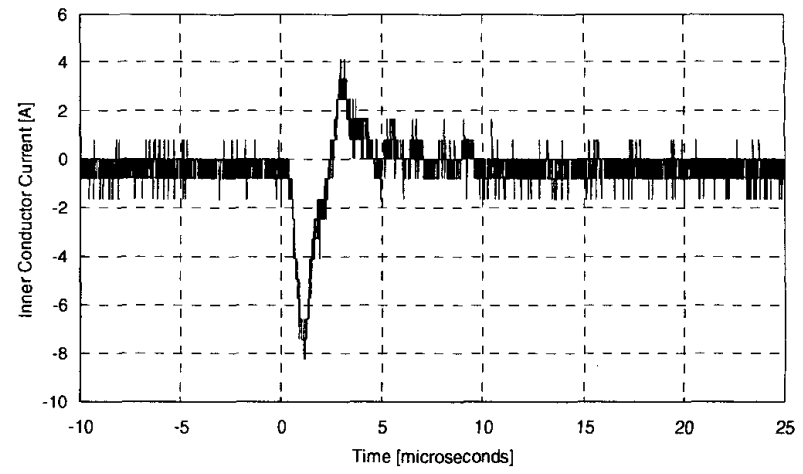

(c)

Fig. 7. Event recorded on July $25^{\text {th }}, 2002$. Stroke location 2.

(a) Horizontal magnetic field. (b) Induced current in the cable shield at IS2. (c) Induced current in the inner conductor at IS2

In this section, we present two sets of measured data for which the impact position was determined by correlating our records to data obtained from the US National Lightning Detection Network (NLDN).

The inner conductor was terminated at each end in $50 \Omega$, and the magnetic field sensor was placed $45 \mathrm{~m}$ from IS1 as indicated in Fig. 4, oriented to measure primarily the magnetic field component perpendicular to the cable.

Figure 8 presents the experimental data corresponding to the two natural events occurred on 26 August 2002 at 19:14:51 GMT (Strike \#N1) and 19:32:12 GMT (Strike \#N2), respectively. The relative position of the two flashes is 
indicated in Fig. 9.

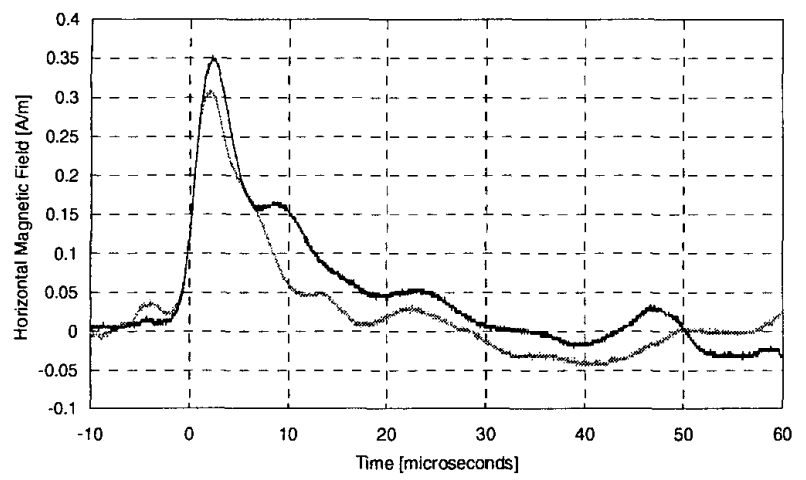

(a)

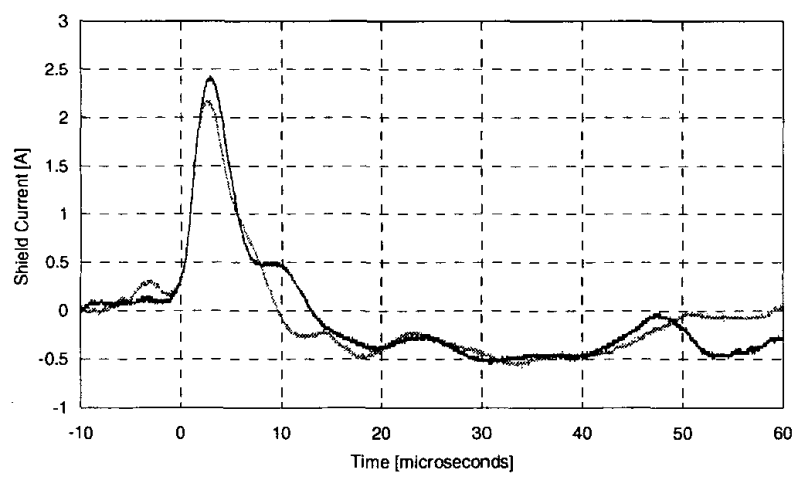

(b)

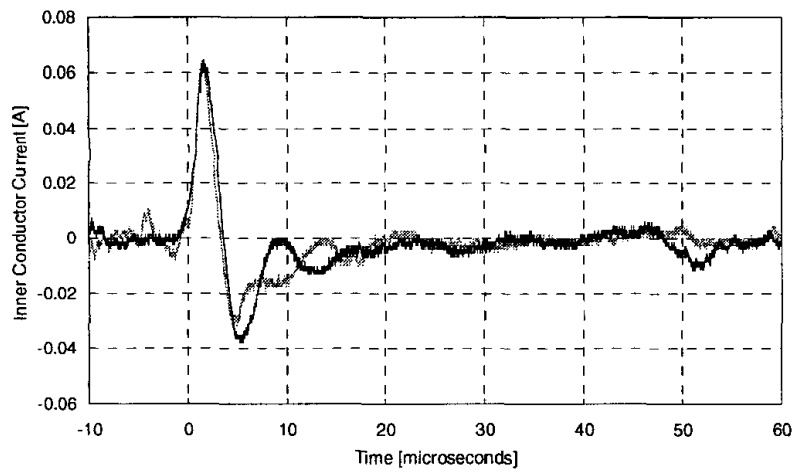

(c)

Fig. 8. Horizontal magnetic field (a), induced current in the shield at IS2 (b), and, induced current in the inner conductor at IS2 (c) for two natural lightning return strokes (from two different flashes shown in Fig. 9)

Dark line: Stroke location \#N1 of Fig. 9

Grey line: Stroke location \#N2 of Fig. 9

A first observation can be made by comparing the triggered lightning event \#1 and the natural events \#1 and \#2 (events in which the cable terminations are the same), where it can be seen that the ratio between the cable induced peak current and the (transverse) magnetic field peak value are similar, namely 7.1 to $6.9 \mathrm{~m}$.

Moreover, it is interesting to observe that the waveform of the induced current in the cable shield is very similar to the waveform of the magnetic field. This can be explained by considering that the horizontal electric field along the buried cable that excites the line [6] can be approximately related to the magnetic field through the surface impedance [2]. The resulting horizontal electric field has a waveform similar to the time-derivative of the magnetic field. Since the induced current in the cable shield is obtained by integrating the horizontal electric field along the cable, it will have a similar waveshape to that of the magnetic field.

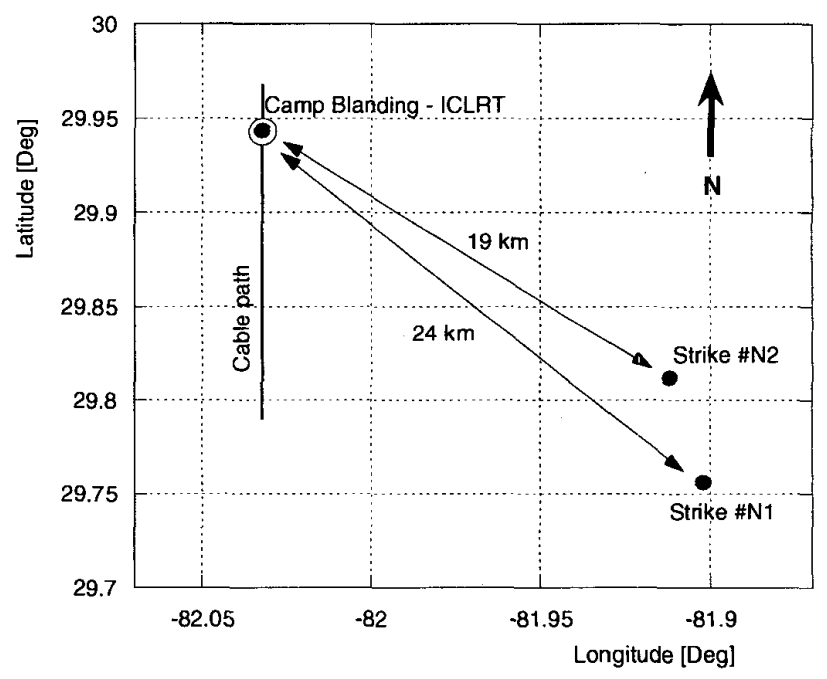

Fig. 9. Lightning stroke locations relative to the buried cable.

\section{CONCLUSIONS}

Experimental results obtained at the International Center for Lightning Research and Testing (ICLRT) at Camp Blanding, Florida have been presented and discussed. Currents induced by triggered and natural lightning events were measured at one end of a shielded buried cable, both in the cable shield and in the inner conductor. The horizontal magnetic field was also measured. For the natural lightning events, the recorded waveforms are correlated with the data obtained by the U.S. National Lightning Detection Network (NLDN).

It is shown that the induced current in the cable shield can reach values of about $100 \mathrm{~A}$ for close stroke locations (within $100 \mathrm{~m}$ ). The induced current in the cable shield is characterized by a pulse width shorter than that of the corresponding magnetic field at close range; while at distant ranges, the induced current waveshape becomes very similar to that of the magnetic field.

Further, for the considered configuration, the induced current in the inner conductor is characterized by a bipolar waveshape. Additionally, due to the high value of the cable transfer impedance, the current in the inner conductor is a non-negligible fraction of the shield current. As a consequence, the common weak coupling assumption used in calculating the response of such a cable might be inadequate.

The obtained results can be used to validate models of underground cables illuminated by lightning electromagnetic fields. 


\section{REFERENCES}

[1] A. Galván and V. Cooray, "Lightning induced voltages on bare and insulated buried cables," Proceedings of the $13^{\text {th }}$ International Zurich Symposium on Electromagnetic Compatibility, pp. 191-196, Zurich, February 1999.

[2] V. Cooray, "Underground electromagnetic fields generated by the return strokes of lightning flashes," IEEE Trans. Electromag. Compat., vol. 43, no. 1, February 2001.

[3] P.P. Barker, T.A. Short, A.R. Eybert-Berard, J.P. Berlandis, "Induced voltage measurements on an experimental distribution line during nearby rocket triggered lightning flashes," IEEE Power Delivery., vol. 11, no. 2, April 1996.
[4] M.I. Fernandez, V.A. Rakov, M.A. Uman, "Transient currents and voltages in a power distribution system due to natural lightning," Transmission and Distribution Conference, 1999 IEEE, Vol. 2 , 1999.

[5] P. Degauque and J. Hamelin, "Compatibilité électromagnétique," Dunod, Paris, France, 1990.

[6] F.M. Tesche, M. Ianoz, and T. Karlsson, "EMC analysis methods and computational models," Wiley Interscience, New York, 1997.

[7] A. Borghetti, C.A. Nucci, M. Paolone, F. Rachidi, "Characterization of the response of an overhead line to lightning electromagnetic fields," Proc. of the 25th International Conference on Lightning Protection 18-22 Sept. 2000 , Rhodes Greece 